Meta

Journal des tradlucteurs

Translators' Journal

\title{
Humor and Translation: Evidence from Indian English
}

\section{Qaiser Zoha Alam}

Volume 34, numéro 1, mars 1989

Humour et traduction

Humour and Translation

URI : https://id.erudit.org/iderudit/004646ar

DOI : https://doi.org/10.7202/004646ar

Aller au sommaire du numéro

Éditeur(s)

Les Presses de l'Université de Montréal

ISSN

0026-0452 (imprimé)

1492-1421 (numérique)

Découvrir la revue

Citer cet article

Zoha Alam, Q. (1989). Humor and Translation: Evidence from Indian English. Meta, 34(1), 72-78. https://doi.org/10.7202/004646ar d'utilisation que vous pouvez consulter en ligne.

https://apropos.erudit.org/fr/usagers/politique-dutilisation/ 


\title{
HUMOUR AND TRANSLATION : EVIDENCE FROM INDIAN ENGLISH
}

QAISER ZOHA ALAM

Ranchi University, Bihar, India

\begin{abstract}
"The Railway does not belong to your father", "Where have you gone and died?", "Does my lap bite you?", "No one can stop anyone's mouth" are statements made by characters in certain Indian novels in English. Translators, in fact, often literally translate oft-repeated Indianisms. When translation from one language into another is attempted, certain things occasionally show oddities and discrepancies. Sometimes such odd uses heighten artistic effect, enhance realistic tinge or produce comic situations. Many of them, however, are there because of ignorance. Untranslatability (linguistic, cultural and collocational) also frequently confronts a translator.

Roland Barthes once said that he absolutely refused to translate anything (Diot: 185). Talking of humour, in particular, Diot finds the operation a desperate one - "While the denotations can roughly be translated into a different language, the connotations cannot. They resist the process of exportation and perish in the shipping." Robert Graves calls translation "a lie", "a polite lie". Translators, it may be interesting to recall here, have also been labelled as "traitors". Undoubtedly, literal meanings are often notoriously inadequate guides to actual usage (Nida). The socio-cultural and economic backgrounds of the respective areas, in many cases, produce baffling though amusing predicaments. That is why, both the deep and the surface structures should be taken note of. The French translator E. Dolet was, as we gather, strangulated to death and all his writings put to flame as his translation of Plato was considered to be unfaithful to the original. Faithful translations, it goes without saying, are seldom useful.

The exact sets of semantic components of the language are no doubt significant but the translator is supposed to see how these components fit into "the much broader communicative patterns of the language" - "how what is said fits into what is not said" (Nida: 345). For instance, while translating idioms, "the sets of semantic components must be entirely redistributed". "An analysis of functional roles of different participants" (Arya: 20) can bring out useful facts. A bilingual or multilingual who possesses two or several grammars (Smith and Wilson, Chomsky) cannot wholly depend on his intuition in this matter. Catford thinks that a text can be analysed in terms of contextually relevant situational features. Catford calls them situational distinctive features. "In the same way that the surgeon operating on the heart cannot neglect the body that surrounds it, so the translator treats the text in isolation from the culture, at his peril" (McGuire: 14). In the English tradition "taking off one's hat from one's head" is a symbol of showing respect, whereas in the Indian context "taking off one's turban/cap from one's head" is a mark of disrespect.

Therefore, the communicative equivalence and the different stylistic and registral variations of both the source language and the target language should be borne in mind while translating because the translator will be called upon to make the appropriate syntactic and lexical adjustments. One's early step, therefore, should always be to identify the register of the source language text. The translator should not be oblivious of the language varieties like regional dialect, temporal dialect, class dialect, idiolect, etc. Ulrych
\end{abstract}


mentions the Italian voto which will be translated as vow in religious register, as vote in political register and mark when referring to academic performance. The Italian accusare may simply mean accuse but in a legal register it may mean charge and in a medical register to feel. It has been found that English words tend to be polysemous and Japanese words tend to be monosemous. As we study the following, we find "cold" in all the English sentences but the corresponding Japanese sentences do not share any one word:

$\begin{array}{ll}\text { English } & \text { Japanese } \\ \text { I feel cold } & \text { samuke-ga suru } \\ \text { It is cold } & \text { samui } \\ \text { cold soft drinks } & \text { tsumetai nomimono } \\ \text { I've caught (a) cold } & \text { kaze-o hiita }\end{array}$

The same goes for hot.

$\begin{array}{ll}\text { English } & \text { Japanese } \\ \text { I feel hot } & \text { netsuppoi } \\ \text { It is hot } & \text { atsui } \\ \text { hot water } & \text { netto (or atsui yu) }\end{array}$

A person who knows that "tour" means "a package tour" will be surprised when asked (in Japan), "Would you take a tour of our house?"

The constraints of collocation should not be lost sight of as, otherwise, situations may become rather comic, e.g., "The tea is too light for me" in Indian English. Ulrych talks of the Italian verb dichiarare which may be translated into English in a number of ways, e.g., lo dichiarò suo erede - he made him his heir ; vi dichiarò marito e moglie I pronounce you man and wife ; nulla da dichiarare - nothing to declare. It is the translator's job to decide from the linguistic and situational contexts whether in Italian $I$ suo $i$ occhi brillarono - his/her eyes "glistened with tears", "flashed with indignation" or "sparkled with joy". Ulrych (16) shows the wide range of possible equivalents for rubare with the help of the following stylistic scale displaying the degree of formality:



The Vende Bible used for a long time the term pfumedzanya for "reconcile" in passages which speak of God "reconciling the world to himself" whereas the term literally means "let someone become rich at another's expense". The Bible talks about "separating the sheep from the goats" on the day of judgement and we need not explain that sheep stand for favorite persons whereas goats symbolize the opposite. A translation like this, however, will simply upset people in Central Africa where goats are highly prized and sheep serve as almost "despised scavengers". When "Hell" is described as "a place where fire never goes out", the people of West Africa feel attracted towards it, as their idea of a bad place would be a cold place, and not a hot one.

Lehmann and Verma ("Syntactic Irregularities") have rightly suggested that conventional expressions and expressions used as phatic communion are best translated by the equivalent conventions in the other language, substituted mechanically and not by looking at the meanings of the constituents. Otherwise, the things would look strange and ridiculous. The German greeting Guten Tag should be translated as "Hello" in English 
because the exact English translation of Guten Tag i.e., "Good Day" would simply be laughable. The same would be the effect of the Japanese expression Sayonara, if it is translated as If it must be so and not as "Good Bye". The Italian word ciao is used as a form of greeting equally on arrival and departure. Even the English expressions Good Morning, Good Afternoon, and Good Evening, etc. have no exact equivalents in Hindi and other Indian languages. The Hindi greeting term Namaste can serve all these purposes. In much the same way, the English expression "How do you do" is culture bound. Its literal translation in Hindi, i.e., Tum kis tara karte ho has an entirely different sense.

A machine translation will be crude and brutally honest and that is why it often makes us laugh. A word-for-word or rank-bound translation results in humorous situations. The Hindi translation of the English sentence "It's raining cats and dogs" as Kutte aur billiyaN baras rahe haiN will be rank bound and just a mockery. The simple German sentence Diese kurze gemeinsame Ueberiegung ist eine art experiment mit uns selbst gewesen is a long sentence and translating longer sentences gives rise to more complex problems and produces more laughable situations. In this sentence the most serious problem is the position of the verb. The appropriate translation should be "The short joint reflection has been a kind of experiment with ourselves" and not "Has a kind of joint experiment with ourselves been". The German expression Uns selbst is translated ourselves and not $u s$ self. The English verb go has a certain meaning in sentences like "He's going home" though in "He's going steady" the verb has an absolutely different meaning i.e., "being in love". In "He had to go", "go" may carry several entirely different shades of meaning. The translation of trick sentences or ambiguous sentences often creates difficulties. Tosh has drawn our attention to the difficulties in the treatment of "discontinuity" and cites as an example "Will you look the list over". When a speaker in the United Nations quoted this excerpt from the Bible, "The spirit is willing but the flesh is weak" the computer translated it into other languages as "The wine is good but the meat is bad" (Lehmann: 226).

Many in India translate the Hindi sentence Aap kya kahte haiN, Lal Sahib? as "What you say, Mr. Lal". Since there is hardly anything like indirect form of narration in Hindi our people often come out with translations like "Do you know where does he live". In English in India, as an impact of the first language, the tag is almost always "isn't it" or "no", whatever the main question. When Indians produce such translations as "Your both hands are dirty", "My all friends are here" and "This my friend is very poor", the word order in the source language is generally the cause of the problem.

Translation in largely a literal style results in a number of typical errors of articles in India as there is no article worthy of the name in Indian languages. Also, translations like "I am seeing a man outside" are very common in our country because such an expression is close to our usage although, as we know, "see" and a few other verbs are seldom used in a continuous form. It may be interesting to quote Dr. Amarnath Jha here: "Who is there in the United Provinces who does not know freeship? All of us know what a student means when he says that he is engaged in teachery and soon hopes to get headmastery. Must we insist on all this when this all is nearer our own usage ?' It is because of Hindi that in reply to "Aren't you coming to dinner tonight ?" many say "Yes, I am not" or "No, I am coming". There is no concord, as can be easily noticed, between the two parts of the sentences here. The correct English equivalent should be "No, I am not" or "Yes, of course I am".

The translator who comes out with "I wented there yesterday" does so on the analogy of "wanted", "parted", etc. On the analogy of "the above statement" he generates "the below statement". A translation like "after abusing me he left saying he would see me outside the college" may be unintelligible to native speakers of English and "The warden 
reached in time and cooled the matter" and "You cannot get a good job without some source" may be unacceptable to them as well. When asked to explain what they understood by the expression "her face-cut is very impressive" in a translated passage, some native speakers of English came out with rather amusing interpretations - She has good bones; her hair-cut is very impressive; her facial scar is very striking; she cut her face badly, poor girl; it sounds as though she has been in a knife fight, or that she cut her face while shaving.

As Arya (20) has shown through analysis of translated passages, even the translation of the preposition "to" in "to a bridge" may cause difficulties. It may be difficult to decide whether the proper translation (in Hindi) is tak, ke pas or par. If voh London gya is translated into English as "He went London", it may be because of the Hindi version which, literally speaking, will be "he London went" in English. "To" does not have any equivalent in the Hindi sentence here. Luckily, we do not come across many mistakes of this nature. The Hindi "se" is expressed both by "for" and "since" without realizing that their occurrence is rule-governed. "Going by walk" is a common use in South India perhaps on the analogy of "going by car" and "going by bus", etc. During an experiment conducted by the present writer, a student came out with "They look at very beautiful". The fact that many of these prepositions have a number of meanings - "of" has 63 meanings listed in the Oxford English Dictionary - further complicates the job of a translator. H.G. Wells asks whether or not the Chinese language has a grammar. Where a sensible Englishman would remark, "Why walk in the ancient ways?" Wells gives the Chinese equivalent as "Affairs, query, imperative, old". The literalness of the observation gave Wells another mistaken opinion that Chinese is also devoid of metaphor (121).

Sometimes new lexical items are needed to talk about things and thought processes for which there are no equivalents or near equivalents in the target language. English does not have equivalents of Hindi kal and parsoN. Kal may be used for "yesterday" or "tomorrow" whereas parsoN may mean "the day after tomorrow" or "the day before yesterday".

The kinship terminologies of the source language and target language particularly make the task of a translator difficult. For instance, "co-brother" or "co-brother-in-law" has a culturally determined value in India. There is only one word "uncle" in English for Hindi's chacha, tau, mama, phoopha, mousa or khaloo and only one word "aunt" for chachi, tai, mami or mamani and mousi or khala. The English "brother-in-law" has two equivalents in Hindi, jija or bahnoi and sala. The words colony, prepone and almirah, etc., as used in India may appear rather arbitrary to a native speaker of English. The same may be said about English expressions like bread of illegality, pin-drop silence and your good name, etc. When bus is used for coach, latrine for toilet and marketing for shopping these choices certainly look arbitrary. Likewise, as there is only one lexical item in Hindi for both "fingers" and "toes" i.e., ungli, we find translations like "leg fingers" and "hand fingers".

Reduplicative words which occur extensively in Indian languages in a variety of semantic functions often produce hilarious situations in exact translations. The underlined verbs in the following sentences are in their reduplicated structures of present imperfect, past perfect and gerundive forms respectively (Abbi : 125):

i) vo calte calte gir paRaa

he walking walking fell down

He fell down while he was walking

ii) Zaid kursi per baithe baithe thak gaya

Zaid chair in sitting sitting got tired

Zaid got tired of sitting in the chair (for too long). 
iii) maaN ne ro ro karapna dukhRa sunaaya

mother crying crying her grief told

Crying, the mother told about her grief.

It is particularly interesting to note that whereas moti moti sankheN is a compliment, expressions like mote mote chor convey a thoroughly different image. Sometimes we find translations like "We saw many good good things" (achhi achhi cheezeN) and "My heart became garden garden (baagh baagh) when I saw him". The appropriate translation should be "My joy knew no bounds when I saw him". A repetition of a particular word often shows a change in meaning, "Sate, sate" (Is that so ? in English) is an expression of astonishment in Oriya.

In Tamil (in South India) the people generally avoid making a statement like "I'm going" because, as they perhaps apprehend, it may mean "going from this world". Tamil speakers therefore use expressions like "I'm going and coming" instead of the plain "I'm going". The tendency to translate the Oriya sentence Mo pakhaare kichi paise naahi into English as "I have no money near me" shows that the translator uses the system of Oriya for the system of English.

Indian writers in English have innovated translation equivalents to present the thought processes that cannot be adequately translated into a foreign idiom. Verma ("Syntactic Irregularities") goes to the extent of saying "nip it in the bud", Raja Rao, in a characteristically Indian way, has said, "Crush in the seed". "As if you were cattle/animals/beasts" is a transliterated Indianism. When Raja Rao uses expressions like "like a noble cow", "as a first-calved cow" and "helpless as a calf", he is actually translating equivalents in Indian languages into English. "Ah, this cat has taken to ascetiscism" (Kanthapura, Raja Rao) is in reality a famous Indian saying. "You go like a fish hooked on a string" and "His touch could turn mud into gold" in Arun Joshi's The Strange Case of Billy Biswas and The Last Labyrinth respectively have sprung from Indian usage. "Large eyes were like a lake after a rain" (The Foreigner, Joshi) and the description of Jahanara's hair in Anita Desai's Voices in the City as that "cloud of black hair swaying about the body" have been virtually transliterated. Bhattacharya talks of "each grain a grain of gold" (in So Many Hungers!) and Raja Rao wants the rice to be as fine as a filigree (in Kanthapura). Ahmed Ali remarks, in Ocean of Night: "Nawab looked as if he had won the pearls of the seven seas". In the same novel, the picture of the fickleness of fortune has been borrowed straight from the vernacular - "How fickle is fortune more than a woman's heart". Talking of fortune once again, Ali says, "Fortune is fickle like the moon which lasts but only four days". Ali presents "desire" as "restless like a moth around the flame". This, once again, is almost a literal translation of a well-known Urdu expression i.e., "Shama" and "parwana". The Indian habit of spitting or suggesting spitting to emphasize one's hatred of something or to abuse or ridicule the thing or to show atrocities or an emphatic denial or disapproval of something has been readily translated into English by these writers.

Another aspect of Indian speech is that money is frequently used for comparison. Also, there are often hyperbolic numerical assertions used by these writers. Time and again such instances produce humorous effects:

- I will draw a hundred lines on the earth with the tip of my nose (Coolie, Anand)

- The wife of a hundred husbands (Two Leaves and a Bud, Anand)

- The saying is worth a hundred thousand rupees (Train to Pakistan, Khushwant Singh)

- Whatever you say is right to the sixteenth anna of a rupee (Train to Pakistan, Khushwant Singh)

- Why do you torment me with the cucumber for the dozenth time (The Dark Room, Narayan) 
Certain verbs as used by these writers appear transliterated from Indian languages. "You have been eating my ears" (Train to Pakistan), "You don't eat my head" and "I will take you to eat a little fresh air" (Coolie). "I hear that the girl has rolled many papads" and "You have cut my nose, bitch" (Old Woman and the Cow, Anand) are interesting expressions in this regard. It may not be irrelevant to quote Anand here: "I generally translate or interpret my feelings or thoughts from Punjabi or Hindustani into the English language thus translating the metaphor and imagery of my mother tongue into what is called Indo-Anglo-Indian writing, but what I prefer to call "pigeon Indian" (not "pidgin Indian"). Verma ("Englishization of Hindi") feels that as translation equivalents or corresponding expressions in Indian languages, they are highly idiosyncratic and arbitrary. Verma tries to substantiate his assertion by citing the following examples from Anand's fiction:

- my counterfeit luck (mera khota naseeb)

- Is this any talk? (yeh bhi koi baat hui)

- nothing black in the pulse (daal meN kaala)

- made me sleep illegal (neend haraam kar diya) (77)

Many of the "interesting" abuses and admonitions have been plainly translated from the peculiar Indian (or even regional) day-to-day conversations. For example, "lover of the own sister" (Ocean of Night, Ahmed Ali), "Oh this Gandhi, would he were destroyed" (Kanthapura), "Oh, come on pubic hair" and "son of a black Shaitan" (A Bend in the Ganges, Malgonkar), etc. Animals have been often used for this purpose as is often done in India: "You cannot straighten a dog's tail" (Kanthapura), "Munoo followed him like a dog behind his master" (Coolie), "ari ari, bitch! Do you take me for a buffoon" (Untouchable, Anand). "Curly spoke like an ass" (Two Virgins, Markandaya) and "he began to climb up like a monkey" (Maria, Abbas).

The Indian writers in English translate phrases, sayings and proverbs, too. These are generally the products of a particular culture. That is why an attempt should be made to have semantic equivalents. For example, "My head is eating circles" for the Hindi expression mera sar chakkar kha raha hae (My head circles eating). Other examples include :

- You haven't the strength to kill an aunt and will fight an elephant (Ocean of Night)

- Toba, toba, kill my own village banian, Babujy, who kills a hen which lays eggs (Train to Pakistan)

- He who has the bit stick will have the buffalo (Death of a Hero, Anand)

- He was as yet essentially a pawn on the chessboard of destiny (Coolie)

- Bathe your feet while the Ganges still flows (A Bend in the Ganges)

- Who gave the beak to the bird will also provide it with food (A Bend in the Ganges)

Sheila said at one place in Anand's Coolie, "Hot tea cools your heart in the heat of summer" - almost a literal translation of an aphorism very popular in India. To cite another example from the same book: "You have hardly a place to rest your head of for the night and you build castles in the air like Sheikh Chilli." These translations easily catch the reader's attention. Exaggeration is a quality shared by many of these writers and let it be noted here that exaggeration is a trait that is common to many Indians. In fact, it is because of the almost literal translations that many things that we find in these writings look like trite and commonplace usages. Many of them are often indiscriminately used in our country and have hardened into clichés. Both Raja Rao and R.K. Narayan, for example, have used the expression that somebody "is as a sister to me". We have in Bhattachary's So Many Hungers! "a golden lotus wasting in mud and filth", in Malgonkar's A Bend in 
the Ganges, "the touch of the hand was like a flame", "her fingers were like ice" and "money was spent like water", and in Anand's Coolie, "Why do you hide yourself like women?"

We have argued that a good translator interprets the source language and chooses the most suitable expressions. At the same time, as Krakowian has remarked, "some sort of modifications of a native language concept to fit a foreign language equivalent" may also be necessary. Needless to add, through translation one gets a greater awareness of the complexity of language. The right approach develops our ability to analyse the source language and we acquire a deeper insight into the source language/target language transfer strategies. If these principles are not followed, what we consequently get may be rather ridiculous.

\section{BIBLIOGRAPHY}

ABBI, Anvita (1977) : "Reduplicated Adverbs in Hindi", Indian Linguistics, 38:3, pp. 125-135.

ALAM, Qaiser Zoha (1983) : Issues Linguistic and Pedagogic, New Delhi, Sterling.

ALAM, Qaiser Zoha (1986): "The Image in Indian Fiction in English : A Note on Indianness", Seventh Triennial Conference of ACLALS in Singapore.

ALAM, Qaiser Zoha (unpublished) : Eagle in Flight: A Study of the Image in Indian Writing in English.

ANAND, Mulk Raj (1969): "A Plea for English for Higher Education", Language and Society in India, 8.

ARYA, R.C. (1974): "Conditions of Translation Equivalence", CIEFL Newsletter, 14, pp. 18-22.

CATFORD, J.C. (1965): A Linguistic Theory of Translation, London, Oxford UP.

CHOMSKY, Noam (1975) : "Knowledge of Language", in Language, Mind and Knowledge, K. Ganderson ed., Minneapolis.

DIOT, Roland (1986) : "Humor for Intellectuals : Can It Be Translated ?", WHIMSY, 4, pp. 185-188.

KRAKOWIAN, B. (1984): "The Teacher's Mediation in Students' Vocabulary Learning", English Teaching Forum, $22: 3$.

LEHMANN, Winfred P. (1970) : "Machine Translation", in Linguistics, Archibald A. Hill ed., pp. 213-222.

MEHROTRA, R.R. (1980) : “Long Live Indian English!”, The Times of India, September 20, p. 8.

McGUIRE, S.B. (1980): Translation Studies, New York, Methuen.

NARITA, Kyoto (1986) : "English as Troublemaker for Japanese ESL Students", WHIMSY, 4, pp. 43-45.

NIDA, Eugene A. (1971): "Semantic Components in Translation Theory", in Applications of Linguistics, E. Perren and J.L.M. Trim eds., Cambridge, England, Cambridge UP, pp. 341-348.

SMITH, N. and D. WILSON (1979) : Modern Linguistics, New York, Penguin.

TOSH, Wayne (1970) : "Computer Linguistics", in Linguistics, Archibald A. Hill ed., pp. 225-233.

ULRYCH, M. (1986): "Teaching Translation in the Advanced EFL Class", English Teaching Forum, $24: 2$, pp. 14-17.

VARSHNEY, R.L. (1977) : An Introductory Textbook of Linguistics and Phonetics, Bareilly, India, Students' Store.

VERMA, S.K. (1980): "Some Observations of Englishization of Hindi". Paper presented at the Second International Conference on South Asian Languages and Linguistics, Hyderabad, India.

VERMA, S.K. (1980) : “Swadeshi English", Form and Function, Indian Linguistics, 41:2, pp. 73-84.

VERMA, S.K. (1978): "Syntactic Irregularities in Indian English", in Indian Writing in English, Ramesh Mohan ed., Madras/London, Longman, pp. 207-220.

WELLS, H.G. (1961) : The Outline of History, New York, Garden City Books. 